Check for updates

Cite this: RSC Adv., 2019, 9, 2199

Received 6th September 2018 Accepted 10th January 2019

DOI: $10.1039 / c 8 \mathrm{ra07447j}$

rsc.li/rsc-advances

\section{Continuous flow synthesis of diaryl ketones by coupling of aryl Grignard reagents with acyl chlorides under mild conditions in the ecofriendly solvent 2-methyltetrahydrofuran $\dagger$}

\author{
Chuan-Tao Zhang, ${ }^{a}$ Rui Zhu, ${ }^{a}$ Zheng Wang, ${ }^{a}$ Bing Ma, ${ }^{\mathrm{b}}$ Adrian Zajac, ${ }^{\mathrm{c}}$ \\ Marcin Smiglak, (iD 'c Chun-Nian Xia, ' Steven L. Castle (iD *e and Wen-Long Wang (iD *a \\ An efficient continuous flow sequential synthesis of diaryl ketones was achieved by coupling of aryl Grignard \\ reagents with acyl chlorides in the bio-derived "green" solvent 2-methyltetrahydrofuran (2-MeTHF) under \\ mild reaction conditions (ambient temperature, 1 hour), allowing a safe and on-demand generation of 2-(3- \\ benzoylphenyl)propionitrile with a productivity of $3.16 \mathrm{~g} \mathrm{hour}^{-1}$.
}

\section{Introduction}

Diaryl ketones are frequently used as core motifs for developing pharmaceutical agents. ${ }^{1-3}$ They exist in numerous bioactive molecules (Fig. 1), ${ }^{\mathbf{1 , 4}}$ such as the nonsteroidal anti-inflammatory drug (NSAID) ketoprofen, ${ }^{5}$ the broad-spectrum human anthelmintic mebendazole, ${ }^{6}$ the classical lipid regulating agent fenofibrate $^{7}$ and the therapeutically useful uricosuric agent benzbromarone (BBR) ${ }^{8}$ (Fig. 1). Therefore, development of synthetic methods for diarylketones continues to be a highly active area in synthetic chemistry (Scheme 1). The conventional method is Friedel-Crafts acylation of arenes, which has drawbacks such as the requirement for superstoichiometric amounts of Lewis acid and low regioselectivity., ${ }^{\mathbf{9}, 10}$ Alternative synthetic approaches have been developed, including oxidation of secondary alcohols, ${ }^{\mathbf{1 1}, \mathbf{1 2}}$ acylation of organometallic reagents, ${ }^{13-16}$ transition-metal-catalyzed cross-coupling reactions of carboxylic acid derivatives with organometallic reagents, ${ }^{17-24}$ palladium-catalyzed carbonylative cross-coupling reactions between aryl halides and related compounds with carbon nucleophiles, ${ }^{25-30}$ acylation of (hetero)aryl halides with aldehydes, ${ }^{31}$ decarboxylative cross-coupling reactions, ${ }^{32,33}$ decarboxylative addition reactions, ${ }^{33}$ and other uncommon reactions. $^{34}$ Unfortunately, there remain a number of

${ }^{a}$ School of Pharmaceutical Science, Jiangnan University, Wuxi, 214122, China. E-mail: wwenlong2011@163.com

${ }^{b}$ Hybrid-Chem Technologies, Shanghai, 201203, China

'Poznan Science and Technology Park, Adam Mickiewicz University Foundation, ul Rubiez 46, 61-612, Poznan, Poland

${ }^{d}$ Zhejiang University of Technology, Hangzhou, 310014, China

${ }^{e}$ Department of Chemistry and Biochemistry, Brigham Young University, Provo, Utah 84602, USA. E-mail: scastle@chem.byu.edu

$\dagger$ Electronic supplementary information (ESI) available. See DOI: 10.1039/c8ra07447j limitations with regards to expensive catalysts, safety concerns, and environmentally practical considerations.

Compared to traditional batch processing, flow chemistry represents a powerful technology with several advantages including safety, cost, efficiency, robustness and quality. It is considered an ideal partner with green chemistry, ${ }^{35}$ and is a powerful tool for the pharmaceutical industry. ${ }^{36-38}$ Recently, the Jamison group described an efficient continuous flow synthesis of ketones from carbon dioxide and organolithium or Grignard reagents at ambient temperature and pressure. ${ }^{39}$ The Kim group developed an efficient method for the synthesis of ketones using organolithium reagents and acid chlorides under continuous flow conditions at $-40{ }^{\circ} \mathrm{C} .{ }^{40}$ Unfortunately, most of the solvents used in the synthesis of diaryl ketones are not environmentally friendly. In recent years there has been a trend towards the use of bio-derived, green solvents as replacements for hazardous and/or environmentally-damaging solvents. ${ }^{35}$ In fact, 2-methyltetrahydrofuran (2-MeTHF) is one such solvent that has been developed as a greener alternative to classical solvents. ${ }^{41,42}$ With our interest in developing green organic reactions for the synthesis of diaryl ketones, herein we describe an efficient continuous flow parallel synthesis of diaryl ketones
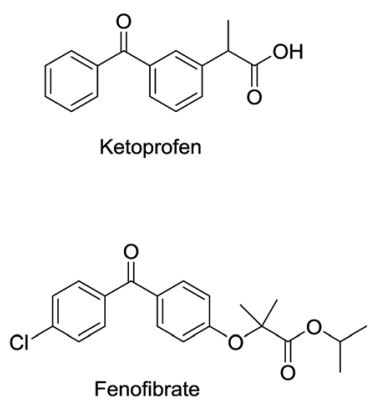
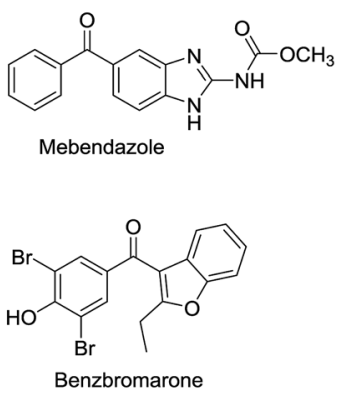

Fig. 1 Pharmaceutical with diary ketone motif. 
a

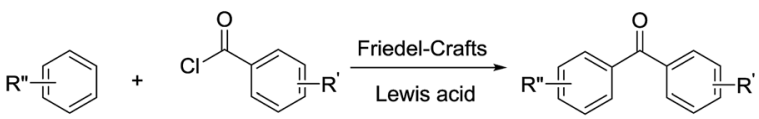

b

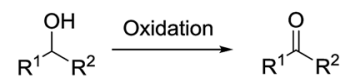

c

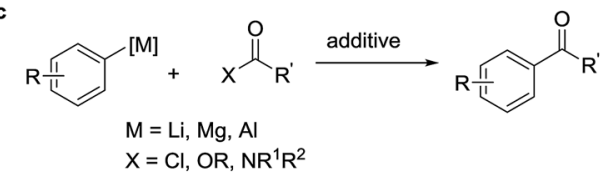

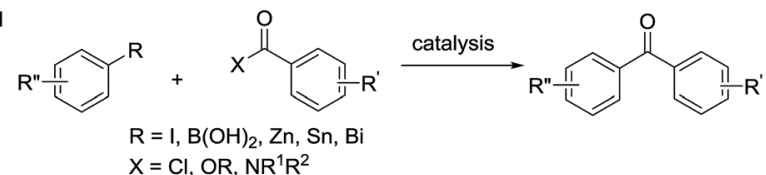

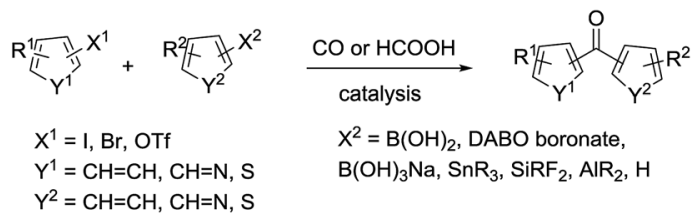

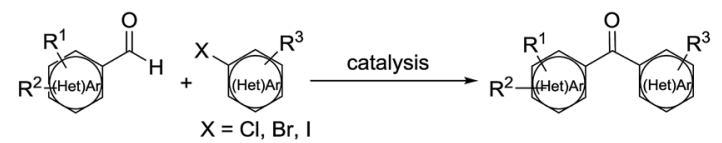

g

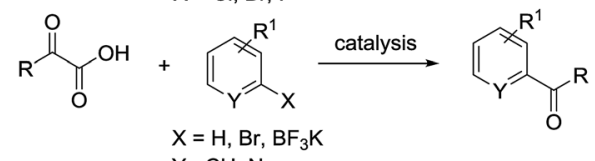

h<smiles>[R]C(=O)C1=C([R])C=C[R1]([N-][Na])C=C1</smiles>

Scheme 1 (a) Friedel-Crafts acylation, (b) oxidation of the corresponding secondary alcohols, (c) acylation of organometallic reagents, (d) transition-metal-catalyzed cross-coupling reactions of carboxylic acid derivatives with organometallic reagents, (e) palladium-catalyzed carbonylative cross-coupling reactions between aryl halides and related compounds with carbon nucleophiles, (f) acylation of (hetero)aryl halides with aldehydes, (g) decarboxylative cross-coupling reactions, (h) decarboxylative addition reactions.

by the direct coupling of aryl Grignard reagents with acyl chlorides without additives at ambient temperature using the bioderived "green" solvent 2-methyltetrahydrofuran (2-MeTHF). We demonstrated the scalability of our method by achieving a productivity of $3.16 \mathrm{~g}$ hour $^{-1}$ in the synthesis of 2 -(3-benzoylphenyl)propionitrile, an important intermediate in the synthesis of ketoprofen.

Table 1 Optimization of the coupling between phenylmagnesium bromide and benzoyl chloride in continuous flow

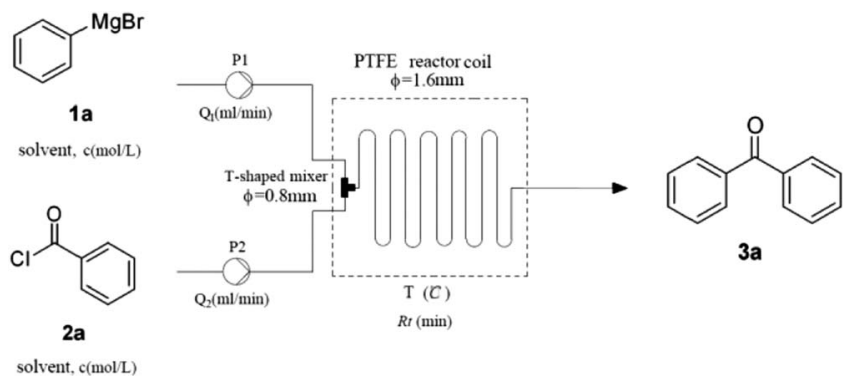

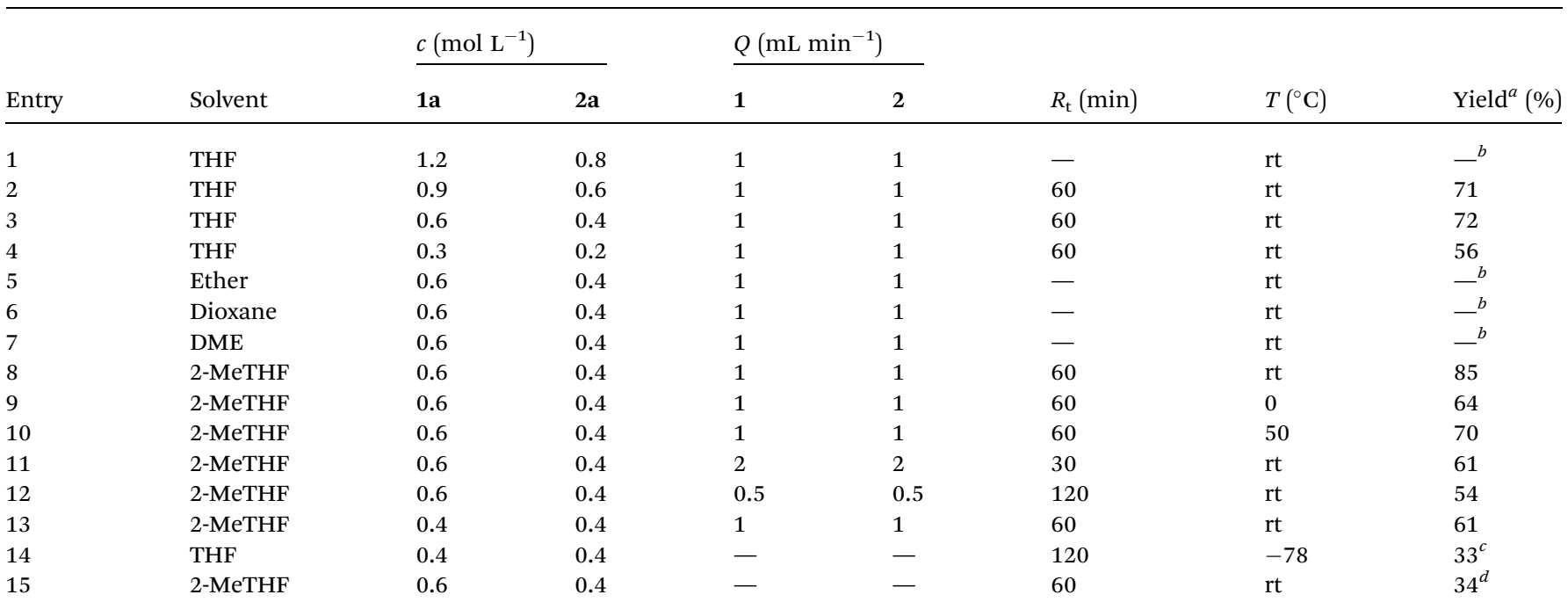

${ }^{a}$ Isolated yield from $4 \mathrm{mmol}$ of 2 a by flash column chromatography. ${ }^{b}$ System clogged. ${ }^{c}$ Yield in ref. $44 .{ }^{d}$ Batch reaction. 


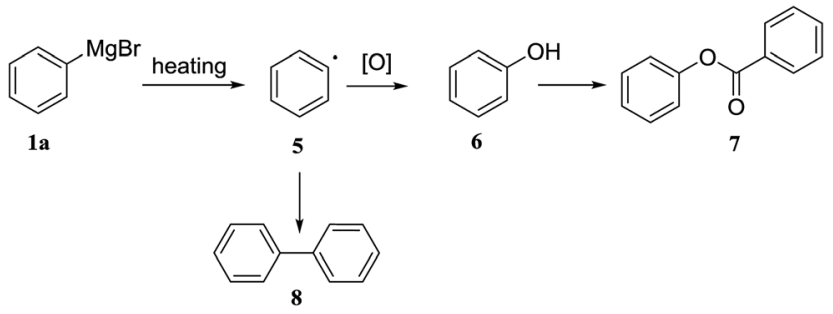

Scheme 2 Possible mechanism for low yield of $3 a$ from the batch process.

\section{Results and discussion}

To optimize the parameters (concentration, solvent, flow rate, residence time and temperature) (Table 1), our initial studies focused on the coupling between phenylmagnesium bromide and benzoyl chloride using a simple continuous system comprised of two standard-pressure HPLC pumps, a T-shaped mixer (Peek 1/32" inner diameter) and a standard PTFE reactor (poly tetrafluoroethylene, 1/16" inner diameter, 120.0 $\mathrm{mL}$ internal volume). Upon exiting the reactor, the reaction stream was immediately quenched with $1 \mathrm{~N} \mathrm{HCl}$. The

Table 2 Reaction of phenylmagnesium bromides $1 \mathrm{a}$ with acyl chloride $2 \mathrm{~b}-\mathrm{o}$ under continuous flow parallel system

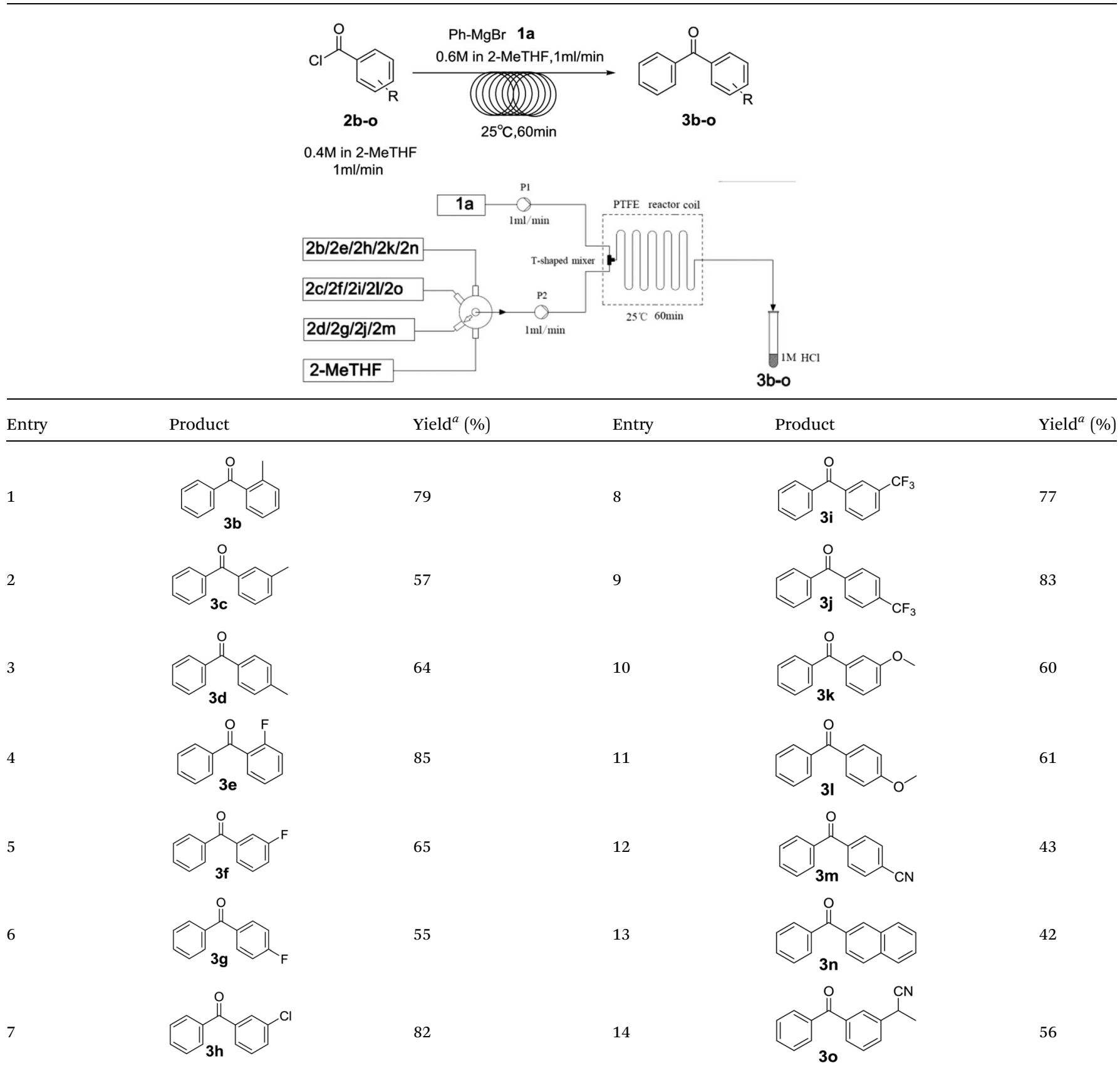

\footnotetext{
${ }^{a}$ Isolated yield from $4 \mathrm{mmol}$ of $\mathbf{2 b - 2 0}$ by flash column chromatography.
} 
Table 3 Reaction of aryl Grignard reagents $1 \mathrm{~b}-\mathrm{h}$ with 2 -fluorobenzoyl chloride $2 \mathrm{e}$ under continuous flow parallel system

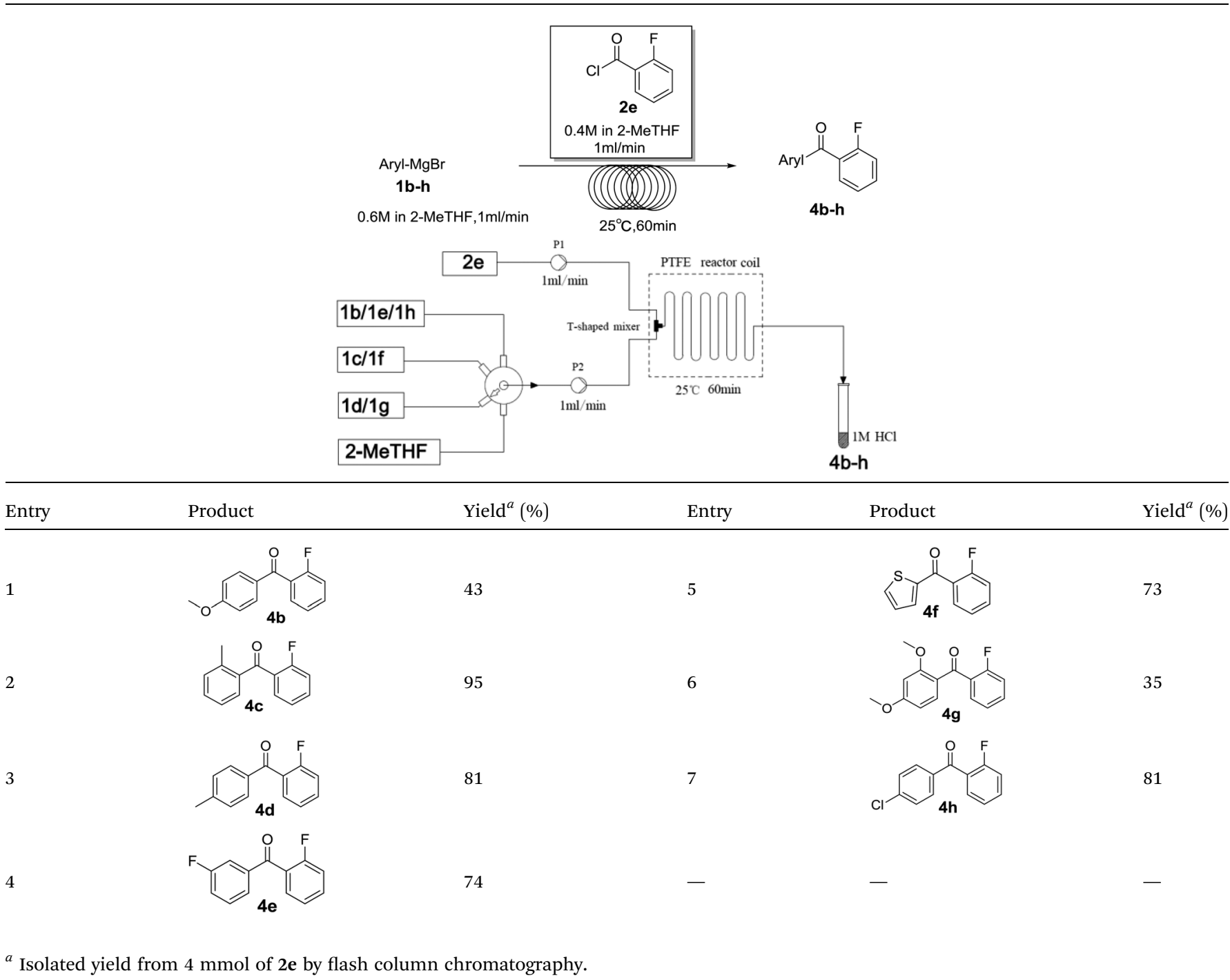

results indicated that concentration obviously impacted the yield, as high concentrations clogged the reactor (entry 1) and low concentrations decreased the yield (entry 4). The optimal concentrations of $2 \mathrm{a}$ and $3 \mathrm{a}$ were $0.6 \mathrm{M}$ and $0.4 \mathrm{M}$ respectively. Some common solvents such as ether, dioxane, and 1,2-dimethoxyethane, were investigated, and the results demonstrated that none were suitable due to clogging the reactor (entries 5-7). The substitution of 2-MeTHF (entry 8) for THF (entry 3) proved to be benign to the reaction, and room temperature led to the highest yield of $85 \%$ (entry 8 ). These results clearly show that this procedure fits the $5^{\text {th }}$ and $6^{\text {th }}$ principles of Green Chemistry very well, which demand biomass-derived solvents that meet the $3 \mathrm{R}$ requirements (reduce, recycle, and reuse) and energy efficiency by employing synthetic methods conducted at mild temperatures and atmospheric pressure ${ }^{35}$ After prolonging the residence time from $30 \mathrm{~min}$ to $120 \mathrm{~min}$ by lowering the flow rate (entries 8,11 , and 12), we determined that a $60 \mathrm{~min}$ residence time afforded the best yield (85\%). Decreasing the stoichiometric ratio of 1a to $2 \mathrm{a}$ from $3: 2$ to $1: 1$ had a detrimental effect on the formation of 3a (entry 13). For comparative purposes the reaction was run as a standard batch process, applying the same concentration of reagents, temperature, and reaction time as optimized in the flow protocol (entry 8). We found that the yield of the batch process to produce compound 3a was $34 \%$, which is similar to the reported yield at $-78^{\circ} \mathrm{C},{ }^{43}$ and, significantly lower than the yield of the optimized flow protocol. Based on the GC-MS of 3a from batch process, the major byproduct 7 was identified (ESI $\dagger$ ). We proposed the possible mechanism that Grignard reagent 1a discomposed to radical 5 when the internal temperature increased by addition of a solution of benzoyl chloride $\mathbf{2} \mathbf{b}$, followed by oxidation to phenol (Scheme 2). ${ }^{44-47}$

Over the past several years, high-throughput chemical synthesis has become increasingly important due to its potential to positively impact the drug discovery process. ${ }^{48-51}$ With the proof of concept, we explored the sequential flow synthesis of a library of diaryl ketones using the optimized reaction conditions. Firstly, we evaluated the substrate scope for various aryl acid chlorides with phenylmagnesium bromide using a continuous flow parallel system adjusted by a five-way valve. The data 
in Table 2 clearly demonstrate that the formation of diaryl ketones from acyl chlorides was quite general and occurred smoothly in the continuous flow system, with moderate to good yields. Among the acid chlorides with meta substituents, yields of fluoride $3 \mathbf{f}(65 \%)$, chloride $3 \mathbf{h}$ ( $82 \%)$, and trifluoromethylated compound $3 \mathbf{i}(77 \%)$ were higher than those of methylated compound 3c (57\%), methoxylated compound 3k (60\%), and 1cyanoethylated compound 30 (56\%). These results indicate that presence of electron-withdrawing groups on the acyl chlorides has a positive influence on the reaction with phenylmagnesium bromide. Interestingly, among the compounds $\mathbf{3 b} \mathbf{b} \mathbf{3 d}$ and $\mathbf{3 e -}$ $\mathbf{3 g}$, the yields of ortho-substituted ketones ( $\mathbf{3 b}$ and $\mathbf{3 e}$ ) were clearly better than those of the corresponding meta-substituted (3c and 3f) or para-substituted ketones (3d and $\mathbf{3 g}$ ).

In addition, the coupling reaction with 4-cyanobenzoyl chloride and 2-naphthoyl chloride afforded moderate yields.

Secondly, we further explored the substrate scope for various arylmagnesium bromides with 2-fluorobenzoyl chloride using the simple flow synthesis system. The data in Table 3 demonstrate that arylmagnesium bromides with electronwithdrawing, electron-neutral, or electron-donating groups were well-tolerated in the reaction with 2 -fluorobenzoyl chloride, affording ketones in moderate to excellent yields (Table 3, entries 1-7). Interestingly, the reaction of $o$-tolylmagnesium bromide with 2-fluorobenzoyl chloride afforded almost quantitative yield (entry 2).

Finally, to demonstrate the scalability of our method, $4.74 \mathrm{~g}$ of 2-(3-benzoylphenyl)propionitrile (3o), an important intermediate of ketoprofen, was straightforwardly produced after $1.5 \mathrm{~h}$ (output $3.16 \mathrm{~g}$ per hour). Yield and purity were similar to that of the small scale reaction, showing that the reaction conditions identified for the production of a few milligrams could be transferred to a larger scale without any further optimization.

\section{Conclusions}

In summary, we developed a novel continuous flow method for parallel synthesis of diaryl ketones using commercially available reagents. The continuous flow nature of our synthesis enabled the facile scale-up of these compounds, which would be highly advantageous for drug discovery. The alignment of our work with green chemistry principles should result in its adoption by the chemistry community.

\section{Conflicts of interest}

The authors declare no conflict of interest.

\section{Acknowledgements}

This work was supported by National Natural Science Foundation of China (21772068), the Department of Science and Technology of Jiangsu Province (BY2016022-37), and National Science \& Technology Major Project "Key New Drug Creation and Manufacturing Program”, China (Number: 2018ZX09711002).

\section{Notes and references}

1 M. H. Keylor, B. S. Matsuura and C. R. J. Stephenson, Chem. Rev., 2015, 115, 8976-9027.

2 X. Qi, L.-B. Jiang, H.-P. Li and X.-F. Wu, Chem.-Eur. J., 2015, 21, 17650-17656.

3 M. L. N. Rao and B. S. Ramakrishna, Eur. J. Org. Chem., 2017, 5080-5093.

4 I. Jabeen, K. Pleban, U. Rinner, P. Chiba and G. F. Ecker, J. Med. Chem., 2012, 55, 3261-3273.

5 E. A. Smith, J. G. Marshall, S. S. Selph, D. R. Barker and C. M. Sedgley, J. Endod., 2017, 43, 7-15.

6 S. C. Zimmermann, T. Tichy, J. Vavra, R. P. Dash, C. E. Slusher, A. J. Gadiano, Y. Wu, A. Jančařík, L. Tenora and L. Monincova, Drug Metab. Pharmacokinet., 2018, 61, 3918-3929.

7 V. Agarwal, M. Bajpai and A. Sharma, Recent Pat. Drug Delivery Formulation, 2018, 12, 40-52.

8 J. Zheng, Drug Metab. Pharmacokinet., 2018, 33, S70.

9 H. Firouzabadi, N. Iranpoor and F. Nowrouzi, Tetrahedron, 2004, 60, 10843-10850.

10 P. H. Tran, H. Q. Phung, P. E. Hansen, H. N. Tran and T. N. Le, Synth. Commun., 2016, 46, 893-901.

11 K.-J. Liu, S. Jiang, L.-H. Lu, L.-L. Tang, S.-S. Tang, H.-S. Tang, Z. Tang, W.-M. He and X. Xu, Green Chem., 2018, 20, 30383043.

12 X. Ye, M. D. Johnson, T. Diao, M. H. Yates and S. S. Stahl, Green Chem., 2010, 12, 1180-1186.

13 F. Wang, A. Lu, D. Huang, Y. Su and X. Xia, Chin. J. Org. Chem., 2015, 35, 1046.

14 J. Nakatani and T. Nozoe, Org. Process Res. Dev., 2016, 20, 1633-1636.

15 X.-j. Wang, L. Zhang, X. Sun, Y. Xu, D. Krishnamurthy and C. H. Senanayake, Org. Lett., 2005, 7, 5593-5595.

16 M. Arisawa, Y. Torisawa, M. Kawahara, M. Yamanaka, A. Nishida and M. Nakagawa, J. Org. Chem., 1997, 62, 4327-4329.

17 S. Shi and M. Szostak, Org. Lett., 2016, 18, 5872-5875.

18 M. Blangetti, H. Rosso, C. Prandi, A. Deagostino and P. Venturello, Molecules, 2013, 18, 1188-1213.

19 S. Shi and M. Szostak, Chem.-Eur. J., 2016, 22, 10420-10424.

20 F. Rafiee and A. R. Hajipour, Appl. Organomet. Chem., 2015, 29, 181-184.

21 D. Lee, T. Ryu, Y. Park and P. H. Lee, Org. Lett., 2014, 16, 1144-1147.

22 D. Wang and Z. Zhang, Org. Lett., 2003, 5, 4645-4648.

23 J. W. Labadie and J. K. Stille, J. Am. Chem. Soc., 1983, 105, 6129-6137.

24 J. W. Labadie and J. K. Stille, J. Am. Chem. Soc., 1983, 105, 669-670.

25 X. Qi, L.-B. Jiang, H.-P. Li and X.-F. Wu, Chem.-Eur. J., 2015, 21, 17650-17656.

26 K. M. Bjerglund, T. Skrydstrup and G. A. Molander, Org. Lett., 2014, 16, 1888-1891.

27 X.-F. Wu, H. Neumann and M. Beller, Chem. Soc. Rev., 2011, 40, 4986-5009. 
28 M. Blangetti, H. Rosso, C. Prandi, A. Deagostino and P. Venturello, Molecules, 2013, 18, 1188-1213.

29 R. Garrison Kinney, J. Tjutrins, G. M. Torres, N. J. Liu, O. Kulkarni and B. A. Arndtsen, Nat. Chem., 2017, 10, 193199.

30 J. Tjutrins and B. A. Arndtsen, J. Am. Chem. Soc., 2015, 137, 12050-12054.

31 T. Wakaki, T. Togo, D. Yoshidome, Y. Kuninobu and M. Kanai, ACS Catal., 2018, 8, 3123-3128.

32 R. Shang and L. Liu, Sci. China: Chem., 2011, 54, 1670-1687.

33 N. Rodríguez and L. J. Goossen, Chem. Soc. Rev., 2011, 40, 5030-5048.

34 Z. Lian, D. U. Nielsen, A. T. Lindhardt, K. Daasbjerg and T. Skrydstrup, Nat. Commun., 2016, 7, 13782.

35 H. C. Erythropel, J. B. Zimmerman, T. M. de Winter, L. Petitjean, F. Melnikov, C. H. Lam, A. W. Lounsbury, K. E. Mellor, N. Z. Janković, Q. Tu, L. N. Pincus, M. M. Falinski, W. Shi, P. Coish, D. L. Plata and P. T. Anastas, Green Chem., 2018, 20, 1929-1961.

36 S. G. Koenig and H. F. Sneddon, Green Chem., 2017, 19, 1418-1419.

37 G. Bernhard, C. David and K. C. Oliver, Angew. Chem., Int. Ed., 2015, 54, 6688-6728.

38 D. Perera, J. W. Tucker, S. Brahmbhatt, C. J. Helal, A. Chong, W. Farrell, P. Richardson and N. W. Sach, Science, 2018, 359, 429-434.

39 J. Wu, X. Yang, Z. He, X. Mao, T. A. Hatton and T. F. Jamison, Angew. Chem., Int. Ed., 2014, 53, 8416-8420.
40 S.-Y. Moon, S.-H. Jung, U. Bin Kim and W.-S. Kim, RSC Adv., 2015, 5, 79385-79390.

41 S. Monticelli, L. Castoldi, I. Murgia, R. Senatore, E. Mazzeo, J. Wackerlig, E. Urban, T. Langer and V. Pace, Monatsh. Chem., 2017, 148, 37-48.

42 R. K. Henderson, C. Jiménez-González, D. J. C. Constable, S. R. Alston, G. G. A. Inglis, G. Fisher, J. Sherwood, S. P. Binks and A. D. Curzons, Green Chem., 2011, 13, 854862.

43 F. Sato, M. Inoue, K. Oguro and M. Sato, Tetrahedron Lett., 1979, 20, 4303-4306.

44 M. S. Kharasch and W. B. Reynolds, J. Am. Chem. Soc., 1943, 65(4), 501-504.

45 M. S. Kharasch and W. H. Urry, J. Org. Chem., 1948, 13(1), 101-109.

46 Z. He and T. F. Jamison, Angew. Chem., Int. Ed., 2014, 53(13), 3353-3357.

47 S. Butini, E. Gabellieri, P. B. Huleatt, G. Campiani, S. Franceschini, M. Brindisi, S. Ros, S. S. Coccone, I. Fiorini, E. Novellino, G. Giorgi and S. Gemma, J. Org. Chem., 2008, 73(21), 8458-8468.

48 G. Schneider, Nat. Rev. Drug Discovery, 2017, 17, 97-113.

49 R. Martín-Rapún, S. Sayalero and M. A. Pericàs, Green Chem., 2013, 15, 3295-3301.

50 L. Maestre, E. Ozkal, C. Ayats, A. Beltrán, M. M. DíazRequejo, P. J. Pérez and M. A. Pericàs, Chem. Sci., 2015, 6, 1510-1515.

51 L. Osorio-Planes, C. Rodríguez-Escrich and M. A. Pericàs, Catal. Sci. Technol., 2016, 6, 4686-4689. 